\title{
In honor of James MacCullagh (1809-1847)
}

On May 14th, 2009, the Royal Irish Academy hosted a symposium to celebrate the bicentennial of James MacCullagh, who once held the Mathematics and Natural Philosophy chairs at Trinity College, Dublin. MacCullagh's main field of expertise was the new wave optics of Young and Fresnel. In his quest for a fuller understanding of this theory, he inaugurated the modern idea of basing a theory on a field Lagrangian and he discovered the mathematical structure that underlies the electromagnetic optics later elaborated by James Clerk Maxwell.

The three articles on MacCullagh published in this issue have been read by their authors at this symposium. The first, by David Spearman, is a concise portrait of MacCullagh the man, the natural philosopher, and the defender of Irish values. The second, by James Bennett, describes the ways in which the cultural and scientific contexts of early nineteenth-century Ireland affected MacCullagh's life. The third, by Olivier Darrigol, is an assessment of MacCullagh's most perennial achievement, his dynamical theory of the optical medium.

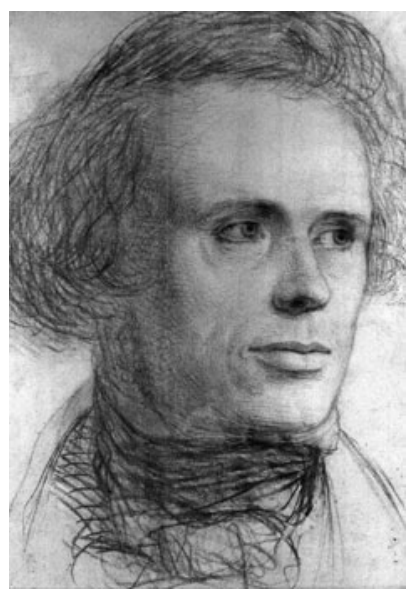

Portrait of James MacCullagh by Frederick William Burton (1816-1900). Black chalk on paper, 1840's.

(c) National Gallery on Ireland. Reprinted with permission.

Olivier Darrigol and Samson Shatashvili 